\title{
4.
}

\section{Playing Whiteness in Crisis in The Last of Us and Tomb Raider}

\author{
Soraya Murray
}

Transactions of the Digital Games Research Association June 2019, Vol 4 No 3, pp 117-146

ISSN 2328-9422

(C) The text of this work is licensed under a Creative

Commons Attribution - NonCommercial -NonDerivative

4.0 License (http://creativecommons.org/licenses/by-nc-nd/ 2.5/).

IMAGES: All images appearing in this work are property of the respective copyright owners, and are not released into the Creative Commons. The respective owners reserve all rights.

\section{ABSTRACT}

This paper examines the white normative figure under duress, through videogames that present a crisis in American narratives of progress: The Last of Us (Naughty Dog, 2013), set in a melancholic post-apocalyptic U.S.; and Tomb Raider (Crystal Dynamics, 2013), a reboot of the now-classic Lara Croft narrative that recasts the heroine as desperate and far from invincible. Using 
key concepts from critical whiteness studies, popular panics around the demographic shifts in the U.S. away from a white majority, and Richard Dyer's theorizations, I show how "making whiteness strange" can decouple it from the normative, and rescue it from unattainable ideals and self-annihilating tendencies. Running the gauntlet between representing universal humanity and traumatized victimhood, whiteness in games takes a beating within a fraught post-9/11 and post-Obama moment of national transition. Through critical analysis of identity politics around whiteness in video games, larger cultural stakes are revealed.

\section{Keywords}

white, whiteness, last of us, Tomb Raider, Dyer, intersectional, culture, cultural studies

\section{INTRODUCTION}

This paper examines constructions of the white normative figure under duress, and particularly, an amassing crisis in relation to crumbling dominant Western narratives of progress. The primary game in question, The Last of Us (Naughty Dog, 2013), portrays a melancholic vision of a post-apocalyptic United States, two decades after an outbreak of "infected"- humans overcome by an airborne fungal pandemic. As the fungus spreads in their brains and slowly takes over their bodies, they are rendered progressively more deformed and rabid. Scrappy factions of survivors operate in desperation, set against a horrific backdrop of civilization gone feral. In this game, the future is sublime and bleak and terrorizing, and it won't be over quickly. The Last of Us has become iconic as a beleaguered, mournful magnum opus, in relation to a cultural moment of anxiety around the United States as an embattled superpower under the dual pressures of economic globalization and environmental catastrophe. In a second example, a cinematic survival action-adventure Tomb Raider (2013), iconic white female protagonist, Lara Croft, is reconfigured from her 
indomitable super-archaeologist-adventurer status into a figure much more vulnerable, surely capable but clearly imperiled. Lara Croft is also a character almost universally discussed in terms of gender; this overburdens possible readings of the character a great deal, for obvious reasons. But, considering the revamped Croft through an analysis of whiteness constitutes intervention that opens up new possible interpretations, for both the Tomb Raider heroine and for an aesthetics of ambivalence that seems to mark some of the most iconic titles in mainstream games today. And like The Last of Us, there is a narrative of loss, disempowerment or disadvantage, of things going horribly wrong. There exists a tension between the figure and a hostile, brutal or unrelenting environment. In short, this paper scrutinizes a moment of selfconsciousness in regard to the interruption of heroic protagonists, as exemplified by these two dominant games that so strongly feature beleaguered forms of whiteness.

I largely focus on constructions of whiteness in visual culture as theorized by film theorist Richard Dyer, alongside critical whiteness studies by scholars like sociologist Ruth Frankenberg and others. Through detailed formal analysis and careful attention to these paradigmatic examples, I critically deconstruct the "normative" invisibility of whiteness and its functioning within mainstream games, at a critical historical juncture in which whiteness is in crisis. The questions posed are, then: within the cultural context of their development and release, how do these mainstream games represent whiteness? How is whiteness seen in them? And what does this tell us about the prevailing sentiments in a fraught cultural moment in which power dynamics are shifting? This should not be confused with unilateral statements (that I would never make) regarding a group of people that one might collectively call 'white'. And, this does not have to do with presumptions of what individuals within that group might be thinking. This has everything to do with systemic issues of representation and cultural construction, and observation of the visual politics at play, as it relates to an ideological construction of whiteness. 
These games tap into a larger cultural malaise arising from the changes occurring within a U.S. context. That is to say, in the following discussion of whiteness in relation to the games in question, it should be understood that I see whiteness not as "invisible" or "empty" or normative, but as occurring within the context of a dominant culture that is in fact intensely aware of whiteness, and an entertainment industry that is likewise tuned in to what will resonate with the dominant market.

\section{THE LAST OF US}

The Last of Us presents a scenario steeped in loss, melancholia and an aesthetics of ambivalence. It tells the story of Joel, a white working man and single parent, and his pale, slight, blond daughter, Sarah, with whom he has a close relationship. It is clear that Joel has long, strenuous workdays, and is under duress-he is not well-off and is clearly represented as doing his best despite the odds. Initially playing in the third person as "Sarah", players wander the domestic space and learn from contextual clues and secondary characters that their Austin neighborhood is in turmoil, and in fact the problem goes far beyond their location, having spread to both national coasts. An aggressive infection is spreading that renders those who contract it violent. In the aftermath of a car accident that occurs in the chaos, the player character role switches to Joel, as he tries, unsuccessfully, to protect his injured daughter from the pandemonium ensuing. Sarah is mistakenly shot by a soldier who has been ordered to execute the potentially infected, and she dies in Joel's arms. Even though all this happens in the dark of night, her skin and hair glow inordinately in relation to the other characters, who are male.

In the aftermath of these events, the player is reintroduced to the primary playable character, Joel, some twenty years later. He is now a smuggler, and a much more disheveled, worn down figure to whom far too much has happened. We find him in a postapocalyptic Boston that is a crumbling police state. The 'new 
normal' is a daily existence of scavenging and desperation, barter and bribery, limited resources and survivalism. Alongside a female companion named Tess, who initially acts as a guide for the player through the perils of the militarized zones and quarantined areas, Joel grimly traverses the environs. As an action adventure survival-horror game, stealth, puzzle-solving and effective utilization of the environment are key, but the game also uses a crafting system that allows for the development of weapons from found objects, in addition to guns and other arms. Killing is a core mechanic, although it is framed mostly as grim and necessary for survival, rather than spectacularized and heroic. While it is immediately clear that Joel is resourceful and jaded enough to address his circumstances pragmatically, he (as the playable character) is clearly traumatized and endangered. His look and manner are consistent with mainstream representations of a "heartland" American male: presumed straight, Caucasian, shortish dark hair and beard, assertive carriage, able-bodied, and wearing a western-style shirt and jeans. He doesn't talk much, and is acerbic when he does.

After a series of scenarios that function as veiled in-game tutorials on controller usage, and to relay content that contextualizes the aftermath Joel lives in, we meet Ellie (voice and motion capture by Ashley Johnson). She is fourteen years old, and a precocious, darkhaired, wide-eyed vulnerable young white tween who predictably invokes the memory of his lost daughter, Sarah. She is the new externalization of his seriously compromised sense of hope. Protected by a revolutionary militia called "The Fireflies", who mysteriously deem her important, Ellie becomes the precious cargo Joel and his partner Tess are enlisted to smuggle safely away from the Boston quarantine zone. Tess is lost soon after, and the remaining gameplay mostly consists of the odyssey undertaken between Joel and young Ellie to ferry her to safety and fully understand her significance to the militia. Along the way, Joel and Ellie grow close as they face tremendous peril, hardship, loss, failures and ethical quandaries. 


\section{CULTURAL CONTEXT: WHITENESS AFTER 9/11}

My use of the term "whiteness" is not one of simple classification of skin color, but a term that has come to define a much more phantasmagoric position that takes into account ideological dimensions of meaning ascribed to this complex construction. Whiteness studies, or what has subsequently been called "critical whiteness studies” arose from postcolonial and postmodern theory made popular in the 1970s and 1980s, with a strong surge in the U.S. in the 1990s. As Tyler Stallings summarized this moment, "vocabularies and strategies had developed based on the notion that forcing the dominant culture to recognize itself-to name itself, when for so long it had claimed to have no name-was the first step toward dismantling it.”(Stallings, 2003, 17) Ruth Frankenberg, outlines three key facets of whiteness: "First, whiteness is a location of structural advantage, of race privilege. Second, it is a 'standpoint,' a place from which white people look at ourselves, at others, and at a society. Third, 'whiteness' refers to a set of cultural practices that are usually unmarked and unnamed.”(Frankenberg, 2000, 447) She goes on to discuss the ways in which naming whiteness displaces its "structured invisibility", reconnecting it to complex histories of colonialism, imperialism and assimilation; it productively racializes whiteness; and it opens up possibilities for antiracist whiteness.”(Frankenberg, 2000, 451)

There are many and disparate approaches to critical whiteness studies, most of which are associated with Frankenberg's delineations, but which also study other dimensions of the subject such as white privilege (Lipsitz, 2006), the stratification of various groups according to race and its effects, ontological questions of whiteness, and the connections between race and power. (Brander Rasmussen et al., 2001a, 6) While there are numerous intellectual resources in many established disciplines that engage with whiteness, I focus primarily on interventions in visual culture, as well as a uniquely post-9/11, and subsequent post-Obama election 
moment of anxiety in which the stability of white heteronormative patriarchy is threatened.

The perception that something has changed in terms of white dominance, has taken hold, and "we live in a time when many White Americans perceived themselves to be living in an increasingly 'Brown' America in which they will soon be outnumbered and in which 'being White' is given less overt cultural significance. For these White Americans,” Thomas Ross observes, "it is a time of racial anxiety." (Ross, 2005, 225)

The World Trade Center bombings in New York on September 11 , 2001, referred to as " $9 / 11$ ", complicated this sense of white racial anxiety further, by traumatizing the public imaginary of white America through, among other things, the ideological configuration of the victims of 9/11 as white firefighters and white Wall Street business people caught in the towers. (Ross, 2005, 235) Of course, the reality was much more diverse-especially given the international melting pot of New York. Nevertheless, there emerged a strong binary opposition between white "heartland" (i.e. straight and Christian) authentic American families, and Arablooking (i.e. Muslim) men, whose resemblance to the hijackers of the doomed planes installed a new fear into the hearts of white America. The mass media incessantly covered the losses of families that conformed to the flag-flying, white picket-fenced, white ideal that came to stand in for all victims of the tragedy. Images of the Twin Towers collapsing were looped on the news, while pre-existing images of the towers were scrubbed from popular culture so as to avoid distressing Americans while the nation healed. If there was any doubt about the global attack on an American "way of life", this event was politically managed to effect an absolute nationalist, jingoistic sentiment that has religious, cultural, and racial overtones. (Ross, 2005, 238-40) 
This perspective is similarly supported and enhanced by Frankenberg, who, in the same year, wrote "Cracks in the Façade: Whiteness and the Construction of 9/11" which connects the nomenclature around this event with ideological connections to whiteness and "narratives of innocence, goodness, Godliness and strength.” (Frankenberg, 2005, 559) Ultimately calling attention to how "alongside national self-importance, sense of entitlement and the actuality of US military and economic might, is a brittle and fragile sense of nationhood which easily senses danger everywhere”, Frankenberg entreats readers to honor the dead by not imbricating them in false narratives of whiteness and Americanness. (Frankenberg, 2005, 569)

Complicating this is the reality that whiteness, in an American context, has shifting associations which fluctuate between: a racial categorization, an ideology of power relations, a Western term of normativity, an "empty" signifier for lack of authenticity or ethnicity, a marker of violence and terror for some, and an extension of an institutionalized and pernicious form of categorization installed during European colonial and imperialist expansion. (Brander Rasmussen et al., 2001a, 10-13) This is shored up through visual culture, of which video games are now a part, and it is through analysis of these forms of dominant culture that insight can be gained.

\section{DYER'S WHITENESS}

Insofar as visual culture is concerned, Richard Dyer's White is most urgent for this discussion, though the author never specifically addresses video games. Surveying a broad array of Western image-making practices such as photography, cinema and print media, Dyer presents a clear-eyed assessment of images that purport to present "nonparticular" (i.e. white) identities by underscoring their particularities and addressing the underlying presumptions that accompany their imaging. (R. Dyer, 1997) This text is key for my own analysis of the two games in question, 
although, given their playable dimensions, I expand upon the innovations of Dyer in constructive ways for the medium.

Dyer unpacks the normative and "invisible" nature of whiteness in both representation and the ways in which the visual is spoken of. While the film scholar clearly identifies that "the privilege of being white in white culture is not to be subjected to stereotyping in relation to one's whiteness," he also points out the contradiction that this perceived sense of being the normative, betrays a persistent and underlying fixation with whiteness. (R. Dyer, 1997, 11)

The nonparticular status of white identity as normal or universal identity subsequently described is often perceived as unthinking or oblivious in its usage. However, importantly, in his book-length examination of whiteness, Dyer does not let those engaged in so-called 'normative' representation off the hook; rather than excusing them on the basis of ignorance, he points instead to the self-consciousness of these representations:

most of the time white people speak about nothing but white people, it's just that we couch it in terms of 'people' in general. Research-into books, museums, the press, advertising, films, television, software-repeatedly shows that in Western representation whites are overwhelmingly and disproportionately predominant, have the central and elaborated roles, and above all are placed as the norm, the ordinary, the standard. (R. Dyer, 1997, 3)

He discusses whiteness in terms of its tremendous instability, the fluidity with which certain ethnic groups, like Jews and the Irish, may have held different positions in terms of the color hierarchy, as a means to police the privileges whiteness affords. (R. Dyer, 1997, 48-57) Pulling away from a discussion of whiteness as "white ethnicity", and certainly not white nationalism, he is instead deconstructing whiteness itself and conceiving of how it can be possible to go about "making whiteness strange". (R. Dyer, 1997, 4) Covering a history of the term (in accordance with several cited venerated scholars, including Winthrop Jordan and Martin 
Bernal), he finds the modern origination of the term "white" to be connected to the American colonies, and deeply imbricated in the Christian tradition. (R. Dyer, 1997, 66) It is all innocence, purity, cleanliness and beauty; but the logical outcome of the ideal of whiteness is ultimately unattainable and self-annihilating.

\section{THE LAST OF US AND IMPERILED WHITENESS}

The impossible, imperiled position of whiteness is embodied in Joel, the bedraggled protagonist and primary playable character of The Last of Us. He is self-consciously normal and "everyman” in his manifestation, possessing neither superhuman powers nor the skills of a supersoldier. He is vulnerable, emotionally shut down and compromised, definitively an anti-hero. At some point in the narrative, his young partner, Ellie, takes on the protector/provider role after he is seriously injured. Several extended analyses of this game utilize a feminist approach that variously interprets the game as either propping up gender norms or displaying a sense of mourning toward the loss of heteronormative unity. (Joyce, 2014; Voorhees, 2014)

Joel is in many ways a cypher for the so-called American average hardworking man, come to the end of his rope and emptied out of his inherent value in a society that has changed around him. Dyer's examination of this male everyman type is best exemplified in his analysis of the 1993 crime drama directed by Joel Schumacher, Falling Down, which describes the events in the day of an "ordinary" middle class man (to be read as white man) who finds himself at war with the "everyday world" (to be read as the increasingly diverse world) and descends in to a nihilistic meltdown after losing his job, his family and his sense of purpose. In the case of this film, it is exactly the main character's ordinariness through which the anxieties around the endangered nature of the white man comes into focus: "Falling Down's success may derive from its expression of the state of play in 
the contemporary construction of whiteness, between a renewedly respectable supremacism, the old everything and nothing-inparticular hegemony and the fear of an annihilation that will be the realisation of our [whites'] emptiness."(R. Dyer, 1997, 222) Importantly, the Falling Down model of white masculinity ideologically melds ordinariness and a constructed alterity, something that is repeated to excellent effect in The Last of Us. Dyer ultimately summarizes the film as "an allegory of the death of the white man, or at any rate, the white man as endangered species."(R. Dyer, 1997, 217) Teetering at the mouth of this gaping emptiness, Joel of The Last of Us demonstrates a similar disorientation, but it comes in the form of a deathward-looking melancholia that is staved off for the purpose of protecting Ellie against a hostile environment.

In the case of The Last of Us, this is exemplified in the glowing white, blond Sarah (daughter of Joel), whose life is lost in the game's inciting incident. The ineffectual role Joel played in protecting his child is presumably the origin of his bitterness, and this psychology becomes transferred onto Ellie, a surrogate young white girl. While she has more agency, Joel repeatedly refuses to permit her a weapon, and persists in a dynamic through which he is placed in a protectorate role. In one scene, for example, Joel comes across a bow and Ellie asks to use it, proclaiming, "I'm a pretty good shot with that thing." Joel responds, "How "bout we just leave this kind of stuff to me." Ellie protests: "Well, we could both be armed. Cover each other." Joel admonishes her: "I don't think so." Given that it would be fairly difficult to shoot one's self using a bow and arrow, it is more likely that Joel is attempting to spare Ellie the traumatizing experience of killing. This is emphasized through the various fatherly shielding gestures enacted during gameplay: for example, while crouched together in a cover position, Ellie often nestles under Joel's arm; or, while standing, he protectively places an arm across her body like a barrier against harm. She is also represented as physically diminutive next to his strong stature. She represents the purity, cleanliness of spirit, a normative sense of beauty, and throughout 
the narrative Joel's reticence for Ellie to have the agency to kill (by possessing a weapon) strongly signals his desire to preserve that innocence. Eventually this dynamic shifts, but it comes late in the game and only when it is clear that Joel cannot complete objectives singlehandedly.

Describing the specific role of white women in the colonialist fiction, Dyer asserts that they:

...voice a liberal critique of empire and are in part to blame for its decline. Because of their social marginality and because, when they do do anything, they do harm, the only honorable position for them, the only really white position, is that of doing nothing. Because they are creatures of conscience this is a source of agony. Yet it is an exquisite agony...Women take the blame, and provide the spectacle of moral suffering, for the loss of empire. For this, they are rewarded with a possibility that already matches their condition of narrative existence: nothing. (R. Dyer, 1997, 205-6)

In an uncanny reflection of this very conundrum, Ellie's character, who is born into the post-pandemic space, moves about within the flickering embers of Western culture as an embodiment of innocence - that is, in the absence of her actual usefulness as an agent of society's redemption and cure, she is instead ideologically overdetermined as an externalization of conscience, as Joel's last grasp of his own humanity, and as a youthful figure who symbolizes the very possibility of a future. For much of the game, he is configured as protector, and she occupies the role of a resourceful kid who needs defending. Her expressions of wonder the first time that she walks in the woods, or sees an old record shop, point to a sense of discovery and a freshness in her perspective that Joel lacks. Yet, increasingly, she constitutes a liability for Joel, in that she causes him to deviate from a selfserving routine that has kept him alive. Through gameplay, it is revealed that her role is ultimately to do nothing. And of course, true to Dyer's characterization, she ultimately saves nothing, as well. In this case, Joel shares with her the blame for the downfall of culture through his refusal to allow Ellie's brain matter to be 
harvested in the pursuit of a cure. While she is unveiled as a kind of sacrificial lamb, this actual role goes unfulfilled, in no small part due to Joel's unwillingness to let go of her. There is an argument to be made, as well, for the connectedness between the imaging of the ruins of empire, and the female figure, who, according to Dyer, often operates as the embodiment of a critique, while simultaneously being configured as the cause of the downfall itself. Joel is, after all, imperiled by his growing attachment to a girl, who holds the keys to humanity's survival, and who will force him to face insurmountable odds.

One possible reading of the Last of Us - as an extension of the apocalyptic narrative of contagion or zombies, is that the foe (virus/undead attacker) represents the externalization of an inner threat. By making it into a targeted enemy that can be identified, isolated and destroyed. In The Last of Us, what is enacted again and again - as a kind of technology that is engaged with-is a traumatized, frustrated white masculinity. Gerald Voorhees writes of The Last of Us:

...trauma and loss are the most frequently recurring ideas. Death colors the tenor of the game and defines the most poignant moments of the narrative: Sarah bleeding out in Joel's arms, Tess in a pool of blood on the capitol floor, Bill's lover hanging from a ceiling fan, Sam and the two bullets from Henry's gun, Joel's incapacitation at the university campus, David stealing the last shreds of Ellie's faith in humanity, and of course, the world that died during the open credits and the dream of resurrecting that world that died with Marlene’s final plea to Joel.

But it's the death of heteronormativity, heroic masculinity in Joel's case and heterosexism in Ellie's, that some players and commentators can't seem to get over. (Voorhees, 2014)

The latter part of this observation relates to additional downloadable content, called The Last of Us: Left Behind, released in 2014. It contains additional narrative around Ellie, and depicts a same-sex kiss between her and another young female survivor, 
Riley. Many hailed this moment as a "breakthrough" for its deviation from heteronormativity that is especially pronounced in game representation. (Hamilton, 2014a)

It is true that trauma and loss operate at a frontal position in the game, as Voorhees describes. However, what is also at work is Dyer's theory of "white death": that is to say, that whiteness has associations with “deathliness” (R. Dyer, 1997, 208) and that whiteness is ultimately configured as being dead and bringing death, something that the film theorist goes on to explicate through his interpretation of the zombie film. (R. Dyer, 1997, 209-11) There is a palpable sense in which the configuration of whiteness as purity, otherworldliness, a certain rigidity of body, and pallor begins-for Dyer-to approach the horizon of death as the absolute expression of whiteness. Through his interpretation of "startling images of white people as the dead devouring the dead" it becomes clear that on the ideological level, whiteness as death results in a kind of inevitable, almost hysterical catharsis linked to finally capitulating to the horrors of its own making-something which Dyer identifies as the apotheosis of whiteness itself: "to be destroyed by your own kind.” (R. Dyer, 1997, 211) While misery is at the forefront, more central is the notion of whiteness as endangered and fundamentally unsustainable, albeit through its own complex machinations.

In the game, this is relayed in all the ways that Voorhees has described. But it is also self-contained in the very character of Ellie, the white female, who is at once the embodiment of innocence to be protected, the bearer of the moral suffering for the way things have become, and the unwitting cause of the decline of (American) empire. This is illustrated through the final catharsis of the game, in which Joel learns of Ellie's true importance from the Fireflies leader, Marlene. Ellie's purpose, as someone immune to the fungus, is to submit to an invasive brain matter harvesting that would provide key samples necessary for developing a vaccine. Her function, in other words, is to die. This is relayed in a cutscene in which Marlene (who, according to the narrative, values 
Ellie) attempts to convince Joel of this moral position. However, after all that he and Ellie have been through, Joel is strongly bonded to the girl; so he opts to save her.

What follows is extensive combat in which an injured Joel takes on the Fireflies, in a maze-like defunct medical facility, while locating a sedated Ellie and snatching her from the operating table before it is too late. In an upending of all for which Joel and Ellie strived for throughout their travails, our anti-hero must kill everyone who knows of Ellie, in order that she may be liberated from the burden of her responsibility to humanity. In terms of actual playability, the player has no choice but to pursue this killing, if they wish to continue playing the game. No ethical option to save or not save Ellie is offered. The prototypical last stand that Joel engages in, with the limp Ellie in his arms, is bitter. It evokes the vulnerable body of Joel's dying daughter, and this is confirmed when he calls Ellie "Baby Girl"-a term of endearment he once reserved for his own child. It also generates ethical questions in the player regarding the pyrrhic victory of saving Ellie at the cost of a possible cure.

While the player must be goal-oriented in their efficient killing of the Fireflies, the context of this bloodbath suggests that it is highly problematic, and forecloses the possibility of heroism on behalf of humanity. One may be a hero only to Ellie, and only nebulously so. After preserving her from immediate physical harm, in a conventional shooter/action sequence that culminates with killing Marlene, Joel and Ellie escape. In a cut-scene, the player sees Joel and Ellie returning to a small community of uninfected, where it is presumed that they hope to live. Ellie asks one last time whether it is really true that the Fireflies militia has stopped searching for a cure, and therefore it is no longer necessary for her to sacrifice herself to this cause. While it may be true that her brain matter may not result in a cure (we learn from a found doctor's recording that past attempts have not been successful) it is patently untrue that the doctors no longer want to use her to create a vaccine. Although it is unclear whether Ellie believes Joel, she acquiesces 
to his declaration that he speaks the truth. Thus, the dying of the world is symbolically sealed in a lie that Joel tells Ellie, out of his weakness for her.

Voorhees locates the difficulty players have in negotiating the value of Joel's choice as one that issues from the player's own relative attachment to normative heroic masculinity. (Voorhees, 2014) He suggests that the degree to which the player has a melancholic response to the decision is directly connected to their perception that his heroic American masculinity is compromised by his irrational choice made on the basis of weakness, sentimentality and selfishness. A much healthier "mournful" response is one through which the player can see Joel as "flawed but redeemable" (Voorhees, 2014) in the face of highly problematic forms of American maleness. In both cases, the presumption is that there is an erosion of the normative, to which a player will undoubtedly have a strong response. This is likely to be at play to some degree. However, I am less interested in the debate around the difficult ending, than how the representation of Joel and Ellie-as iterations of desperate whiteness set against ruin and abolished social structures-resonated so strongly with audiences.

This suggests a response, not only to the individual narrative of the game, but the conditions or socio-political moment within which that kind of narrative would be understood as impactful. The most notable of these in U.S. culture was the re-election of President Barack Obama in 2012, which drew a dramatically more negative response from Republicans than his first election four years prior. Among the reactions associated with the news of reelection were notable paroxysms of anxiety from major right-wing public figures, like Rush Limbaugh, Ted Nugent, Ann Coulter, Bill O'Reilly, Donald Trump and many others, who declared that traditional America had "died", that they had to take back the nation, or strive to make America "great” again. (Krieg, 2012; Horsey, 2012) YouTube videos documenting Republican emotional meltdowns were circulated. Several reported murders and attempted murders were associated with perpetrators who 
specifically named the cause as distress over the re-election of Obama. There was a small riot on the campus of The University of Mississippi, located in a strongly Republican state whose flag still contains the Confederate battle emblem. What was evidenced was a strong anxiety around the future of the United States, one that carries with it a racialized encoding of what in the nation is being lost, and is greatly at play in the persistence of tropes around imperiled white masculinity in games. What was at play was a response to a perceived shift in power within the nation, evidenced in the displays of grief and profound anxiety, but also forms of visual culture that increasingly resonated with audiences, such as The Last of Us exemplifies.

\section{TOMB RAIDER, WHITENESS AND THE FEMALE HEROINE IN PERIL}

It is worth considering womanhood in particular, in relationship to the ideological category of whiteness. One paradigmatic example from the same cultural moment that can be used to problematize constructions of whiteness in relation to race and gender is the revamping of the representation of Lara Croft. Tomb Raider (2013), developed by Crystal Dynamics and published by Square Enix, is an origin story in which the player meets a youthful Croft on her first expedition. Unlike the Lara Croft of previous games, the hyper-sexualization of her body is notably toned down: while still clad in her iconic tank top, she now wears long pants, and her breasts seem (finally) more proportional to the rest of her body. She is untested, although she is already obsessed with ancient cultures, and is adventurous in the pursuit of this knowledge. Her confidence falters, and she displays much more vulnerability. This is conveyed through body language, dialogue and the learning curve the character faces in the playable aspects of the game. It is telling that one of the most iconic characters in all of video game history underwent such a radical reinvention following an American cultural moment of fear and besiegement. 
As a character, Lara Croft is considered almost exclusively from the perspective of gender. Indeed, despite her popularity with players, her highly contested formulation has become somewhat of an icon for virtually everything that is wrong with the representation of female characters in games. Likewise, the conventional use of a generic white male protagonist has also come under scrutiny, resulting in interventions that seem to embody then break with type, through character development such as in The Last of Us. Anne-Marie Schleiner contests the feminist critique of Croft, declaring her "a product of the mechanization of bodies; her fetishized synthetic beauty resides in her slick and glistening 3D polygons, evolved from clunky robotic forms into attire more appropriate for the information society." (Schleiner, 2001) Presenting a broad array of possible readings, Schleiner advocates for the subversion of gender categories by appropriating and hacking the iconic Lara.

In describing female hypersexualization in relation to Tomb Raider and other games, Jon Dovey and Helen Kennedy assess that, "the visual imagery in many mainstream games seems to be entirely ignorant of the critiques that have been made of these stereotypes in other visual media and appear to import some of the worst examples in an entirely unreflexive and uncritical way.” (Dovey and Kennedy, 2006, 93) Justine Cassell and Henry Jenkins outline the problematics of Croft as a character purported to be liberated and capable, while pandering to chauvinistic teen male interests ("tits and ass", as they put it). (Cassell and Jenkins, 2000, 32) They ponder the potentialities of transgender identification made possible through the male player's engagement with a female avatar.

Helen Kennedy, in her definitive 2002 essay, "Lara Croft: Feminist Icon or Cyberbimbo?” considers the diverging interpretations of this iconic character, in terms of what she calls "gendered pleasures" that occur as a result of play. She surveys the broad array of feminist responses to the polarizing figure of Lara Croft, and importantly attends to the possible transgender readings of 
relations between player and character. Additionally, she underlines the avatar's uncanny vacillation between her objecthood as a heteronormative sexual fantasy figure, and her complete lack of a defined sexual identity. "In the end," she concludes, "it is impossible to securely locate Lara within existing feminist frameworks, nor is it entirely possible to just dismiss her significance entirely.” (Kennedy, 2002) For Kennedy, feminist theory must turn its attention to games, while keeping in mind the computer-mediated particularity of their forms.

There is also an array of responses that interrupt the notion that Croft should be read through gender representation. Most notably, Espen Aarseth's comments on the figure of Lara Croft, contradict the dominant feminist critiques that occurred early on. He suggests that playability changes the terms of engagement, and that, relative to game mechanics, the avatar is best thought of as transparent: “...the dimensions of Lara Croft's body, already analyzed to death by film theorists, are irrelevant to me as a player, because a different-looking body would not make me play differently...When I play, I don't even see her body, but see through it and past it.” (Aarseth, 2004, 48) In this, the game studies and electronic literature scholar attempts to wrestle video games from narrative-based interpretation, identifying them as selfcontained forms - a "new material technology"-as opposed to a continuation of story (with its attendant representations) in interactive form. (Aarseth, 2004, 46) In more recent research, Esther MacCallum-Stewart has returned to the subject, surveying the history of responses to the iconic character, while taking into account Croft's reinvention by a female writer in the 2013 reboot. (MacCallum-Stewart 2014) While there is no shortage of debate around Lara Croft, her whiteness is greatly under-theorized.

Whiteness and femininity are both at play in Tomb Raider (2013). Particularly during the first portion of the game, many of the missions focus on Lara as unprepared, as overwhelmed, and in serious jeopardy. Dyer discusses the notion of the heroine in peril in relation to visual pleasure, which, although related to exhausted 
tropes of female passivity in cinema, is directly relevant to the reinvention of Lara Croft as a woman who is resourceful, yet out of her depth, ambitious but inexperienced and imperiled. ${ }^{3}$ Writing on the cinematic desperate heroine, Dyer observes:

Heroes in jeopardy do something about it; heroines don't. And the pleasure we are supposed to get from seeing these sequences is that of a woman in peril. We're supposed to get off on her vulnerability, her hysteria, her terror. In the way such sequences are put together, we are encouraged to take up a traditional male role in relation to the woman, one that asserts our superiority and at the same time encourages us to feel the desire to rape and conquer. We are superior because we either know more than her (we know that psychopath is there but she hasn't spotted him yet), or because we can see what any sensible person would do but she, foolishly and pathetically, doesn't. (R. Dyer, 2002, 96)

Dyer proceeds to make plain the ways in which the viewer of the sort of rote imagery he is describing is presumptively encoded as heterosexual male, and that this constructed male gaze oscillates between that which is tantamount to a rapist (who sees the unsuspecting heroine's unprotected flesh from a privileged and predatory vantage point) and a savior (embodied in the rescuer who comes to her aid). (R. Dyer, 2002, 96-98) Characterizing this "tendency" in cinema to be organized around what is thought to exemplify heteronormative male sexuality, Dyer sees this impetus as putting women in their place, "as objects of a 'natural' male sexual drive that may at times be ridiculous but is also insistent, inescapable and inevitable. Such representations help to preserve the existing power relations of men over women by translating them into sexual relations, rendered both as biologically given and a source of masculine pleasure.” (R. Dyer, 2002, 98-99) Lara Croft's whiteness accords her a kind of purity. Her adventurer status aligns her with the colonial vision of the white explorer in an exotic land, while her white femininity paints her somewhat as 
a victim, but simultaneously as the critic of-or even the cause of-the downfall of empire.

Lara's deaths are illustrated in various kinds of startlingly gruesome forms including impalement, butchering, being crushed by boulders, gunned down, stabbed, torn apart by wolves, shot with arrows, hacked at, strangled and burned. (Blythe Adams, 2015) These illustrated deaths are far more ghastly than in previous Tomb Raider titles. In addition to their gory detail, they are also notable departures from earlier iterations of the Lara Croft franchise, which paint the heroine as much less fragile, and have a much stronger focus on puzzle solving. Still, this revamped Lara was generally critically lauded, and contained many of the same elements of adventure and discovery for which the franchise is known. (Parkin, 2013; Kollar, 2015; Miller, 2013; Narcisse, 2013; Chambers, 2013)

Survivalism and loss, as well as the identified theft of innocence thematically figure into Tomb Raider in a way that feels very much like The Last of Us. (Parkin, 2013) In this case, the female form of whiteness is cast against the backdrop of a mysterious Pacific island called Yamatai, filled with hostile inhabitants who are cult followers bent on female sacrifice to their Solarii Sun Queen. Separated from her shipwrecked crew, Lara must learn to navigate the terrain alone and, increasingly, defend herself against both the elements and the obsessed, deranged islanders. As opposed to an unflappable heroine, she is the underdog, initially the victim, and must quickly learn to handle herself in the unrelenting environment. She is no daredevil, as she unsteadily negotiates the perils around her. Scavenging again plays a strong role in the playable elements of the game. Players must search for tools and parts that allow Lara to find and upgrade weaponry, and otherwise provide the means for survival. Like The Last of Us, the urgency around finding what one needs, if even in small amounts, feels dire. In addition, the discovery of clues, artifacts and documents that unveil additional knowledge of her location and her attackers provide complexity to the narrative. Like Joel in The Last of 
Us, the scenario presents another traumatized form of whiteness, although in this case, one that interestingly vacillates between the visual representation of a vulnerable female figure, and the urgent drive to protect that playable figure from harm. ${ }^{4}$ This is expressed to great effect in various ways, including the plentiful desperate grunts and cries of the character as she navigates the dangerous terrain. It is also expressed in the small, animated touches such as the way she grasps an injured arm while her character awaits your next move. Although Joel and Lara are both viewed in the third person, from a visual culture perspective, Lara reads differently than Joel due to the overbearing pre-existing image culture around white femininity which informs her reception.

In a brief playable cut scene that received much media attention, Lara is abducted by a male scavenger, who physically intimidates her by suggestively rubbing a hand against her thigh. This scenario was initially described by a representative of Crystal Dynamics as an attempt to abduct and rape Lara, but the language around this was quickly amended to indicate that there was no sexual assault represented. However, the scene is decidedly gendered, and the so-called "pathological situation" which was intended to indicate physical intimidation and fear conveys a strong affective sense of impending sexualized domination. (Schreier, 2012) Thus, the dynamics of simultaneous predator/protector described by Dyer in relation to the embattled heroine is embodied in the player interaction with Lara as a vulnerable woman to be looked at, and also a victim to be saved. Certainly, she is not passive to the degree that Dyer describes in relation to earlier cinematic representations. She finds her agency and transforms into the figure that we recognize, the indomitable Lara Croft. But she too is an embattled figure, set against the backdrop of an uncivilized place, and cast in the role of the victimized other, while mobilizing a visual politics of whiteness that largely goes unacknowledged in analysis. 


\section{CONCLUSION: A TRAUMA NARRATIVE OF WHITENESS}

The overwhelming absence of a discussion of whiteness as core to each of the aforementioned games points to a larger, understudied area in playable media. Namely, whiteness in video games often operates in duplicitous ways as both a universal expression of humanity - which has ideological consequences-and as a specific form of identity politics that goes unrecognized as such. "The combination of extreme whiteness with plain, unwhite whiteness," Dyer explains, "means that white people can both lay claim to the spirit that aspires to the heights of humanity and yet supposedly speak and act disinterestedly as humanity's most average and unremarkable representatives.” (R. Dyer, 1997, 223)

The function of deconstructing these complicated representations is to understand the power at play in these pervasive images. These two games, though inclusive of many themes and dimensions, simultaneously reveal a set of concerns of a social grouping of heteronormative whiteness, particularly in relation to navigating a scenario of losing power and dominance. These are the "aesthetics of ambivalence” of which I speak, affective qualities that trade on notions of the white male normative hero, but which in fact betray a larger form of whiteness that is deeply in crisis, desperate and which strategically mobilizes itself as a form of otherness. It is a whiteness that appropriates the moral high ground of victimhood through its embattled status as a form of alterity, even while it trades on itself as normative.

If we suspend the idea of these games as representing the normative, and consider how they are in fact the expression of a particular group, and if we can make the whiteness of these games "strange", it becomes possible to see several things. In the first case, it reveals a trauma narrative of ideological whiteness that repeats itself unendingly in the innumerable fear-based narratives of contagion, besiegement, apocalypse and the crumbling of civilization. Second, it becomes clear that, rather than merely a strategy for representing a universal form of humanity, these 
games are in fact utterly fixated on whiteness, even while proclaiming themselves as nonparticular. How can both of these function simultaneously? How can whiteness possess the ordinariness of universalism, while also assuming a traumatic narrative of alterity and disenfranchisement? This doublesignification is connected to the effort to preserve whiteness from denaturing it to the point that it becomes specified (and therefore non-dominant) rather than universal. This is mobilized, at least in part, by a representational logic ordered around the normativity of whiteness, and a phobic response to difference. Presented again and again in games as cultural forms are expressions of whiteness as both normative and under duress, unremarkable and exalted, deserving of, and denied that which was deserved. That is to say, these games must be understood as the visual politics of dominant culture and therefore, at the time in which they were made, an expression of the totalizing logics of whiteness.

\section{ACKNOWLEDGMENTS}

Special thanks to Riccardo Fassone, Matteo Bittanti, Torill Elvira Mortensen, and Martin Gibbs. The author also wishes to thank Derek Conrad Murray and the external reviewers for their support and careful attention to this writing.

\section{BIBLIOGRAPHY}

Aarseth, Espen. "Genre Trouble: Narrativism and the Art of Simulation.” In First Person: New Media as Story, Performance, and Game, edited by Noah Wardrip-Fruin and Pat Harrigan, 45-55. Cambridge, MA: The MIT Press, 2004.

Allen, Theodore. The Invention of the White Race. London: Verso, 2012.

Berger, Maurice. White Lies: Race and the Myths of Whiteness. 1st edition. New York: Farrar, Straus and Giroux, 2000. 
Blythe Adams, Meghan. “Andromeda on the Rocks: Retreading and Resisting Tropes of Female Sacrifice in 'Tomb Raider.'” Presented at the History of Gender in Games, Auditorium de la Grande Bibliothèque, Montréal [Québec], 26 June 2015. www.sahj.ca.

Brander Rasmussen, Birgit, Eric Klinenberg, Irene J. Nexica, and Matt Wray, eds. “Introduction.” In The Making and Unmaking of Whiteness, 1-24. Durham: Duke University Press, 2001a.

_. , eds. The Making and Unmaking of Whiteness. Durham: Duke University Press, 2001b. http://read.dukeupress.edu/lookup/ doi/10.1215/9780822381044.

Cassell, Justine, and Henry Jenkins, eds. From Barbie to Mortal Kombat: Gender and Computer Games. 1. MIT Press paperback ed. Cambridge, Mass.: MIT Press, 2000.

Chambers, Becky. "Lara Croft Is Dead, Long Live Lara Croft: Reflections On Tomb Raider.” The Mary Sue (blog). 8 March 2013. http://www.themarysue.com/tomb-raider-review/.

Daniels, Jessie. White Lies: Race, Class, Gender and Sexuality in White Supremacist Discourse. New York \& London: Routledge, 1997.

Delgado, Richard, and Jean Stefancic, eds. Critical White Studies: Looking Behind the Mirror. Philadelphia: Temple University Press, 1997.

Dovey, Jon, and Helen W. Kennedy. Game Cultures: Computer Games as New Media. Issues in Cultural and Media Studies. Maidenhead, Berkshire, England; New York, NY: Open University Press, 2006.

Dyer, Richard. White: Essays on Race and Culture. London; New York: Routledge, 1997. 
- The Matter of Images: Essays on Representation. 2. ed. London: Routledge, 1993.

Frankenberg, Ruth. White Women, Race Matters: The Social Construction of Whiteness. 1st edition. Minneapolis: University of Minnesota Press, 1993.

- ed. Displacing Whiteness: Essays in Social and Cultural Criticism. Durham, NC: Duke University Press, 1997.

- "White Women, Race Matters." In Theories of Race and Racism: A Reader, edited by Les Back and John Solomos, 447-61. Routledge Student Readers. London; New York: Routledge, 2000.

_ "Cracks in the Façade: Whiteness and the Construction of 9/11.” Social Identities vol. 11, no. 6(2005): 553-71. https://doi.org/10.1080/13504630500449093.

Gabriel, John. "What Do You Do When Minority Means You? Falling Down and the Construction of 'Whiteness.'” Screen vol. 37, no. 2(1996): 129-51. https://doi.org/10.1093/screen/37.2.129.

Gallagher, Charles A., and France Winddance Twine. Retheorizing Race and Whiteness in the 21st Century: Changes and Challenges. Reprint edition. London; New York: Routledge, 2013.

Hale, Grace Elizabeth. Making Whiteness: The Culture of Segregation in the South, 1890-1940. New York, NY: Vintage, 1999.

Hamilton, Kirk. "Video Gaming's Latest Breakthrough Moment." Kotaku. 17 February 2014. http://kotaku.com/video-gamingslatest-breakthrough-moment-1524555480.

Hill, Mike, ed. Whiteness: A Critical Reader. New York: NYU Press, 1997. 
Horsey, David. "Obama Win Brings the Great Right Wing Freakout of 2012.” The Baltimore Sun, 13 November 2012. http://articles.baltimoresun.com/2012-11-13/news/bs-ed-horseygop-20121113_1_corporate-welfare-americans-election-results.

Jacobson, Matthew Frye. Whiteness of a Different Color: European Immigrants and the Alchemy of Race. Cambridge, Mass.: Harvard University Press, 1999.

Joyce, Lindsey. “An Uneven Partnership «First Person Scholar.” First Person Scholar (blog). 9 July 2014. http://www.firstpersonscholar.com/an-uneven-partnership/.

Katznelson, Ira. When Affirmative Action Was White: An Untold History of Racial Inequality in Twentieth-Century America. Reprint edition. New York: W. W. Norton \& Company, 2006.

Kennedy, Helen W. "Lara Croft: Feminist Icon or Cyberbimbo?” Game Studies: The International Journal of Computer Game Research vol. 2, no. 2(2002).

Kincheloe, Joe L., Shirley R. Steinberg, Nelson M. Rodriguez, and Ronald Chennault, eds. White Reign: Deploying Whiteness in America. 1. St. Martin’s Griffin ed. New York, NY: St. Martin’s Griffin, 2000.

Kollar, Philip. “Tomb Raider Review: The Descent.” Polygon. 25 February 2015. http://www.polygon.com/2013/2/25/4026668/ tomb-raider-review.

Krieg, Gregory J. "Freaking Out: The Best of the Worst Responses to Obama's Win.” News. ABC News (blog). 8 November 2012. http://abcnews.go.com/blogs/politics/2012/11/ freaking-out-the-best-of-the-worst-responses-to-obamas-win/.

Lipsitz, George. The Possessive Investment in Whiteness: How White People Profit from Identity Politics. Rev. and expanded ed. Philadelphia: Temple University Press, 1998. 
144 Playing Whiteness in Crisis in The Last of Us and Tomb Raider

MacCallum-Stewart, Esther. “Take That, Bitches!” Refiguring Lara Croft in Feminist Game Narratives. Game Studies: The International Journal of Computer Game Research vol. 14, no. 2(2014).

Miller, Matt. "Tomb Raider Review - Old Name, Remarkable New Series.” www.GameInformer.com. 25 February 2013. http://www.gameinformer.com/games/tomb_raider/b/xbox360/ archive/2013/02/25/tomb-raider-review.aspx.

Morrison, Toni. Playing in the Dark: Whiteness and the Literary Imagination. 1st Vintage Books ed. New York: Vintage Books, 1993.

Murray, Soraya. On Video Games: The Visual Politics of Race, Gender and Space. London: I.B. Tauris, 2018.

Narcisse, Evan. “Tomb Raider: The Kotaku Review.” Kotaku. 25 February 2013. http://kotaku.com/5986619/tomb-raider-thekotaku-review.

Painter, Nell Irvin. The History of White People. Reprint edition. New York: W. W. Norton \& Company, 2011.

Parkin, Simon. “Tomb Raider - Review.” The Guardian, 1 March 2013, sec. Technology. http://www.theguardian.com/technology/ gamesblog/2013/mar/01/tomb-raider-video-game-review.

Roediger, David R., Mike Davis, Michael Sprinker, and Kathleen Cleaver. The Wages of Whiteness: Race and the Making of the American Working Class. New Edition. London: Verso, 2007.

Ross, Thomas. “Whiteness After 9/11.” Washington University Journal of Law \& Policy [Whiteness: Some Critical Perspectives] vol. 18, no. 1(2005): 223-43. 
Rothenberg, Paula S., ed. White Privilege: Essential Readings on the Other Side of Racism. 4th ed. New York: Worth Publishers, 2012.

Schleiner, Anne-Marie. “Does Lara Croft Wear Fake Polygons? Gender and Gender-Role Subversion in Computer Adventure Games.” Leonardo vol. 34, no. 3(2001): 221-26.

Schreier, Jason. “Tomb Raider Creators Say ‘Rape’ Is Not A Word In Their Vocabulary.” Kotaku. 29 June 2012. http://kotaku.com/5922228/tomb-raider-creators-say-rape-is-nota-word-in-their-vocabulary.

Schumacher, Joel. Falling Down. Warner Bros, 1993.

Stallings, Tyler. Whiteness, a Wayward Construction. First Edition. Laguna Beach, Calif. : Los Angeles: Fellows of Contemporary Art, 2003.

Voorhees, Gerald. “Mourning Sex «First Person Scholar.” First Person Scholar (blog). 3 September 2014.

http://www.firstpersonscholar.com/mourning-sex/.

Wise, Tim. White Like Me: Reflections on Race from a Privileged Son. Revised Edition. Berkeley: Soft Skull Press, 2011.

Wray, Matt, and Annalee Newitz, eds. White Trash: Race and Class in America. New York: Routledge, 1997.

\section{Gameography}

Crystal Dynamics et al. Tomb Raider [PS4]. Square Enix. Co., 2013. Played 2015.

Naughty Dog. The Last of Us [PS3]. Sony Computer Entertainment, 2013. Played 2014. 
146 Playing Whiteness in Crisis in The Last of Us and Tomb Raider Naughty Dog. The Last of Us: Left Behind [PS3]. Sony Computer Entertainment, 2014. Played 2015. 